\title{
ARCABOUÇO PARA ANÁLISE DE CONFLITOS NORMATIVOS EM SISTEMAS MULTIAGENTES
}

\author{
Daniela Godinho Yabe1; Eduardo Augusto Silvestre ${ }^{2}$ \\ 1,2 Instituto Federal do Triângulo Mineiro \\ danielagodinho1@gmail.com, eduardosilvestre@iftm.edu.br
}

\section{1 - Introdução}

Este artigo descreve uma aplicação visual para tratar de conflitos normativos em sistemas multiagentes. A seção 1.1 define sistemas multiagentes e a seção 1.2 normas e conflitos normativos.

Pretende-se com esse trabalho construir um programa visual que sirva como arcabouço para análise de conflitos entre normas em sistemas multiagentes.

\section{1 - Sistemas multiagentes}

Os sistemas que usam agentes vem ganhando uma maior importância na pesquisa e na prática para o desenvolvimento de aplicações diversas nos últimos anos. Segundo Russell e Norvig (2004), um agente de software é uma entidade capaz de perceber seu ambiente por meio de sensores e de agir sobre esse ambiente por intermédio de atuadores. Os agentes inteligentes podem ser classificados de acordo com a maneira que eles coletam informações e agem no ambiente. No caso de vários agentes cooperando ou disputando entre si, inseridos em um mesmo ambiente e trocando informações, chamamos esse sistema de multiagente (SMA) (RUSSELL E NORVIG, 2004). SMAs são sociedades autônomas, heterogêneas e podem trabalhar a fim de alcançar objetivos comuns ou diferentes (WOOLRIDGE, 2009).

\section{2 - Normas e conflitos normativos}

A fim de lidar com a autonomia e diversidade de interesses entre os diferentes membros, o comportamento dos agentes é governado por um conjunto de normas especificado para regular suas ações (SILVA, 2008). As normas regulam o comportamento dos agentes, com definições de obrigações, proibições e permissões.

Neste contexto, vale ressaltar a possibilidade de existir conflitos entre normas. Os conflitos acontecem quando duas normas regulando o mesmo comportamento estão ativadas e tem restrições inconsistentes (VASCONCELOS ET AL, 2008). Os principais casos de conflito são entre uma norma que obriga e outra proíbe, uma que proíbe e outra que permite e uma que obriga e outra que permite.

Por exemplo, as normas N1 e N2, para o agente $A$ estão em conflito:

N1: Agente A é obrigado a estudar entre $x$ e y N2: Agente A é proibido a estudar entre $x$ e y

A verificação e a resolução de conflitos entre normas em sistemas multiagentes é importante para manter a consistência do comportamento autônomo dos agentes.

\section{2 - Materiais e métodos}

Desenvolveu-se um software, utilizando a linguagem de programação Java, capaz de analisar conflitos entre normas em sistemas multiagentes. Assim, para apresentar a melhor opção de uso do sistema, pretende-se oferecer ao usuário condições de inserção ou importação de normas que serão analisadas e mostradas, caso haja conflitos entre elas.

\section{3 - Resultado e discussão}

A literatura que analisa conflitos normativos carece de aplicações que facilitem a visualização e o estudo de conflitos normativos.

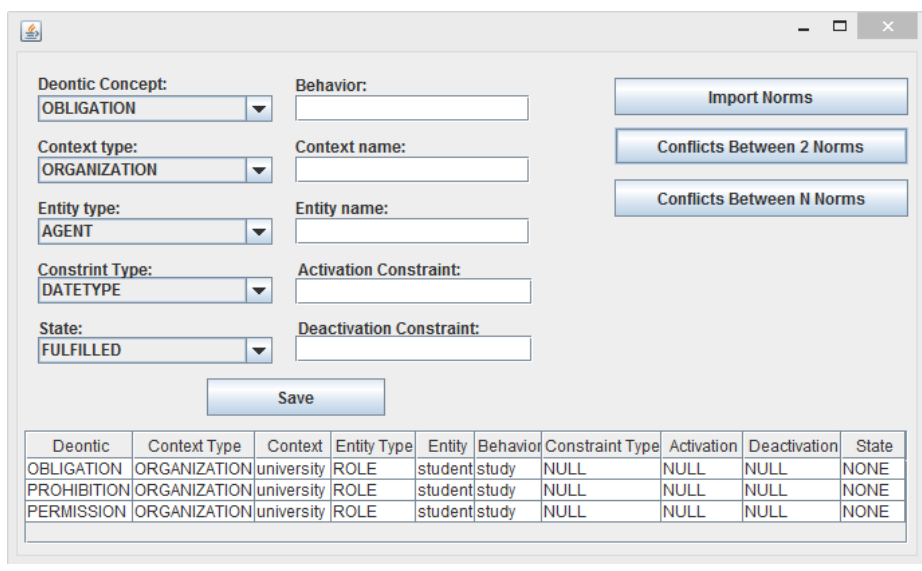

Figura 1 - Tela principal

www.uniube.br/entec - UNIUBE Campus Aeroporto - Uberaba/MG 
Figura 2 - Mensagem mostrando as normas que estão em conflito

A aplicação proposta permite a criação e visualização de normas (Figura 1). Além disso, permite a análise de diversas situações de conflitos normativos. Como por exemplo, o conflito entre duas normas, conflitos entre múltiplas normas, conflitos entre agentes desempenhando vários papéis. Até 0 presente momento, a aplicação tem desenvolvido as funcionalidades necessárias para a análise do conflito entre duas normas.

Neste artigo, a definição de uma norma é a mesma usada por Figueiredo Et. Al. (2011). A definição usada é ampla e cobre definições apresentadas em artigos anteriores. Uma norma $\mathrm{n}$ é uma tupla da forma \{deoC,c,e,a,ac,dc,s\} onde deoC é o conceito deôntico do conjunto \{obrigação, proibição e permissão\}, c é contexto onde a norma é definida, e é a entidade que está sendo regulada, a é a ação a ser regulada, ac é a condição de ativação e dc e a condição de desativação, s é o estado na norma do conjunto \{cumprida, violada, nenhum\}. A aplicação tem abstrações (classes) para representar esta norma.

Duas normas estão em conflito se tem conceitos deônticos conflitantes, estão no mesmo contexto, são referentes a mesma entidade, ação, tem períodos de validade que se interceptam e não foram cumpridas e nem violadas. Suponha a seguinte entrada para aplicação:

$\mathrm{N} 1=\mathrm{O}$ agente estudante é obrigado a estudar na universidade entre $\mathrm{x}$ e y. $\{\mathrm{deo}=\mathrm{O}$, $\mathrm{c}=$ universidade, $\mathrm{e}=\mathrm{e}$ estudante, $\mathrm{a}=\mathrm{estudar}$, $\mathrm{ac}=\mathrm{x}, \mathrm{dc}=\mathrm{y}, \mathrm{s}=$ none $\}$.

$\mathrm{N} 2$ = $\mathrm{O}$ agente estudante é proibido a estudar na universidade entre $x$ e $y$. $\{$ deo $C=P$, $\mathrm{C}=$ universidade, $\mathrm{e}=$ estudante, $\mathrm{a}=\mathrm{estudar}$, $\mathrm{ac}=\mathrm{x}, \mathrm{dc}=\mathrm{y}, \mathrm{s}=$ none $\}$.

$\mathrm{N} 3=\mathrm{O}$ agente estudante é permitido a estudar na universidade entre $\mathrm{x}$ e $\mathrm{y} . \quad$ deoC $=$ $\mathrm{P}, \mathrm{C}=$ universidade, $\mathrm{e}=$ estudante, $\mathrm{a}=$ estudar, $\mathrm{ac}=\mathrm{x}, \mathrm{dc}=\mathrm{y}, \mathrm{s}=$ none $\}$.
Neste cenário, o programa responderá que existe conflito entre as normas $\mathrm{N} 1$ e $\mathrm{N} 2$, e entre as normas N2 e N3 (Figura 2).

\section{4 - Considerações finais}

Esse trabalho teve como objetivo principal construir um programa visual que sirva como arcabouço para análise de conflitos entre normas. A aplicação apresenta diversos algoritmos para verificação de cenários de conflito. Devido a limitação de tamanho do artigo, os algoritmos não foram detalhados.

Para trabalhos futuros, pretende-se implementar novos algoritmos que possam resolver problemas de conflitos normativos recorrentes. A aplicação tem uma arquitetura que suporta inserção de novas funcionalidades.

\section{5 - Referências}

SILVA, V. T. (2008). From the specification to the implementation of norms: an automatic approach to generate rules from norms to govern the behavior of agents. Autonomous Agents and Multi-Agent Systems, 17(1), 113155.

FIGUEIREDO, K., SILVA, S., BRAGA, C., 2011. Modeling Norms in Multi-agent Systems with Norm-ML. In International Workshop on Coordination, Organisations, Institutions and Norms VI. LNAI 6541, Springer, pp. 39-57.

RUSSELL, S., \& NORVIG, P. (2009). Artificial Intelligence: A Modern Approach, 3rd edition. Pearson Education.

VASCONCELOS, W. W., KOLLINGBAUM, M. J., \& NORMAN, T. J. (2009). Normative conflict resolution in multi-agent systems. Autonomous Agents and Multi-Agent Systems, 19(2), 124-152.

WOOLDRIDGE, M. (2009). An introduction to multiagent systems. John Wiley \& Sons. 